Formal publication: https://doi.org/10.1016/j.apacoust.2009.04.004 (C) 2009. This manuscript version is made available under the CC-BY-NC-ND 4.0 license http://creativecommons.org/licenses/by-nc-nd/4.0/ 


\title{
The design and evaluation of an auditory way-finding system in a train station
}

\author{
Julien Tardieu ${ }^{\mathrm{a}, \mathrm{b}, *}$, Patrick Susini ${ }^{\mathrm{a}}$, Franck Poisson ${ }^{\mathrm{b}}$, Hiroshi Kawakami ${ }^{\mathrm{c}}$, Stephen McAdams ${ }^{\mathrm{d}}$ \\ ${ }^{a}$ STMS-IRCAM-CNRS, 1 Place Igor Stravinsky 75004 Paris, France \\ ${ }^{\mathrm{b}}$ SNCF - Direction de l'Innovation et de la Recherche, 45 rue de Londres 75008 Paris, France \\ ${ }^{c}$ College of Art, Nihon University, 2-42-1, Asahigaoka, Nerima, 176-8515 Tokyo, Japan \\ d CIRMMT, Schulich School of Music, McGill University, 555 Sherbrooke St. W., Montreal, Québec, Canada H3A 1E3
}

\section{A R T I C L E I N F O}

\section{Article history:}

Received 9 January 2009

Received in revised form 7 April 2009

Accepted 8 April 2009

Available online 21 May 2009

\section{Keywords:}

Sound signals

Public spaces

Train stations

Soundscape

Earcons

Sound design

\begin{abstract}
A B S T R A C T
Previous studies have shown that auditory cues contribute to the identification of several components of a public space such as the volume, but also the type of activity to which the space is dedicated. This paper demonstrates that solutions to improve way-finding in a public place can be based on providing additional auditory information. A methodical approach in three phases is proposed and applied in the case of a train station. First, problems encountered by travellers in a train station are identified by way of an ergonomic study under real conditions with recruited travellers. The results reveal three kinds of problems: orientation errors, lack of confirmation of direction, and lack of information about the remaining distance to be covered. In the second phase, functional and environmental specifications were developed in order to create sound signals for each identified problem. A sound designer proposed several nonspeech sound signals based on two schemas: a pair of sounds for the orientation and confirmation functions, and a timeline sequence for the remaining distance. Finally, in the third phase, the sound signals were installed in the train station using an experimental broadcasting system and were evaluated in a second ergonomic study using the same method. The results show that the number of orientation errors decreased and that participants felt more confident during their walk. Sound signals for the orientation and confirmation functions were understood and used by the participants. However, the timeline sequence signalling remaining distance was not understood.
\end{abstract}

(c) 2009 Elsevier Ltd. All rights reserved.

\section{Introduction}

Public spaces such as train stations are complex environments, not only in terms of architecture (different types of spaces make up a train station), but also in terms of types of use, such as buying tickets, waiting, watching arrival/departure panels, etc. This complexity can be the source of problems encountered by travellers, such as orientation (e.g. finding a place) or navigation (e.g. reaching one point from another), especially when they are unfamiliar with this environment. This issue is commonly addressed through ergonomic approaches, i.e., an analysis of situated human activity in order to identify the way-finding problems and propose a way to resolve them [1]. Among all the factors that are responsible for way-finding problems, the use of signs has a considerable influence. For example, the work presented in [2] has shown that both textual and graphic signs can reduce the number of way-finding errors in the buildings of a university campus. While visual signs are largely used in public spaces and train stations, the main issue of this paper is to show that way-finding problems encountered by

\footnotetext{
* Corresponding author. Address: STMS-IRCAM-CNRS, 1 Place Igor Stravinsky 75004 Paris, France. Tel.: +33 144784843.

E-mail address: j1tardieu@gmail.com (J. Tardieu).
}

travellers in a train station can also be solved through the auditory modality (e.g. with a sound signalling system). In the case of visually impaired people, auditory displays have been reported to be very effective, e.g., with the use of auditory beacons to specify route waypoints in a GPS based navigation system [3], or short melodic patterns to indicate different important locations (crossings, end of stairs, way out, etc.) in a train station [4]. This paper will concern travellers with normal vision only, but the results may also be relevant for visually impaired people.

In a previous study on the perception of soundscapes in train stations [5-7], it was shown that people have an auditory representation of the different spaces that make up a train station. This representation is mainly built around three types of sound information: sound sources, room effects and human activity. In other words, it appears that we use three types of information to recognize a specific place based on its soundscape. This work shows that sound information contributes to the perception of a place in terms of activity and space. Based on this result, we hypothesized that an appropriate new sound signal added to the soundscape to help travellers in a specific situation would be perceived and would thus be useful to them during their displacements within the station. This does not mean that any kind of sound information is useful, nor that a sound signal can be created in an arbitrary fashion. 


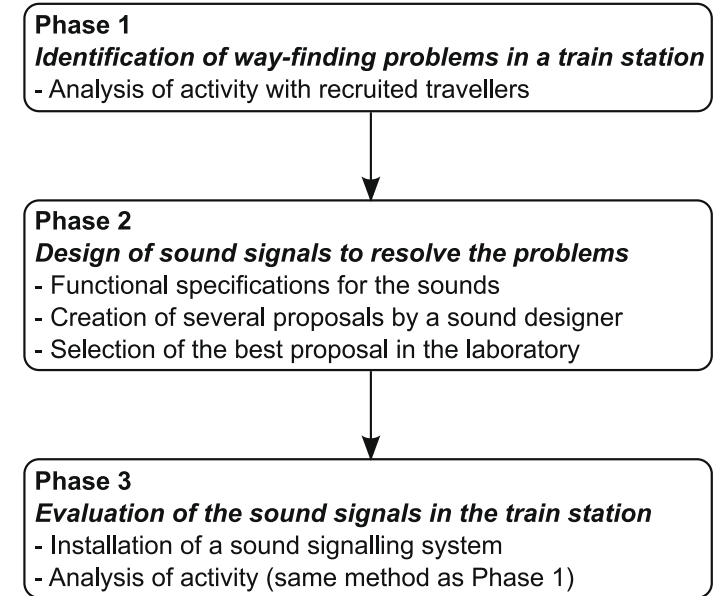

Fig. 1. Diagram presenting the three main phases of the method proposed in this paper.

The question posed here concerns whether it is possible to improve a pathway in a train station using sound signals. Of course, one could say that for a rather noisy place such as a train station, other channels, such as touch or improved visual indicators, would be more appropriate, but the visual modality in such a context is already oversaturated more than the auditory modality, and touch is not obvious for transmitting information as travellers move continuously. We do not intend to impose a particular solution, but our goal is to propose a method for creating sound signals that will help travellers in a train station, i.e., that will solve the problems they encounter using the auditory channel.

The method we present in this paper is divided into three main phases that are presented in Fig. 1. Phase 1 is the identification of problems encountered by travellers in a train station. An experiment was performed under real conditions with recruited travellers, according to ergonomic methods presented in previous work [8-12]. This phase is presented in Section 2. The second phase (presented in Section 3 ) is the creation of sound signals in order to resolve the problems identified previously. This phase is composed of three steps: (1) definition of functional specifications for the sounds, (2) creation of several proposals by a sound designer on the basis of these specifications, and (3) selection of the best proposal with a panel of listeners in the laboratory. The last phase of our method is an ergonomic evaluation of the sound signals in the real context of the train station. A sound signalling system was installed in the station and an experiment was performed using the same procedure as in Phase 1 . This last phase is presented in Section 4, and conclusions are drawn in Section 5.

\section{Identification of actual problems in a specific train station}

The goal of this first phase is to identify one or more problems encountered by the travellers in a train station. Then if the identified problems can be solved using the auditory channel, a sounddesign solution will be proposed (Section 3).

\subsection{Method}

The method is based on an ergonomic study carried out under real conditions (i.e., in a Parisian train station) with travellers recruited for individual sessions. The experiment is divided into two steps:

1. The participant is given specific instructions at the beginning of the session [see Appendix A.1]. Then, they have to follow the instructions alone, and their walk through the train station is recorded on video camera by the experimenter. There is no exchange between the participant and the experimenter along the way.

2. Once the participant has finished his/her walk, an individual interview is performed in order to allow the participant to explain and describe his/her actions during a replay of the video.

This method is based on ergonomic principles introduced by Theureau $[8,10,11]$ for the analysis of practical activities (everyday life activities, as well as skilled activities). Theureau's approach was chosen because it was developed and applied with success in the specific case of identifying problems with a visual signalling system in a Parisian train station [9]. According to this author, a practical activity can be divided into two parts: a part that can be observed and a part that can be commented on. Therefore, the analysis of a practical activity should focus on these two components. In other words, the analysis will focus on what is significant for the actor (the person who performs a practical activity), i.e., on what the actor can show, describe and comment upon. This implies the use of an experimental setup that does not alter the activity of the actor or his/her description of it. Theureau therefore suggests the use of video and interviews.

\subsection{The station}

\subsubsection{Choosing the station}

The experiment must be carried out in a real situation (here, a train station). Thus, a preliminary step is necessary to choose an appropriate situation. Interviews were performed with the managerial staff of the six Parisian train stations, who were asked to report the known problems encountered by travellers. The problems reported during those interviews were mainly related to way-finding difficulties, such as problems finding a platform, a ticket office or services provided in the station. Most of the managers did not give a precise example of those problems, except for Montparnasse Station, where they reported that travellers encountered problems when they had to reach Vaugirard hall, a distant part of the station that corresponds to lines 25-28 (see photo 1 in Fig. 2). In addition, they expressed great interest in having a better characterization of this problem in order to find a solution. For these reasons, we decided to apply our method in this train station, addressing the problem identified by the managers.

\subsubsection{Description of the situation}

The Vaugirard hall entrance (photo 5) is located $300 \mathrm{~m}$ from the main part of the station, comprising lines 1-24. To reach this hall, it is necessary to walk along platform 24 . Three moving walkways (see photos 2, 3 and 4 in Fig. 2) are available to get there more quickly. According to the information collected in the interviews with the station managers, the cause of the problem could be that travellers don't see the first sign that indicates the location of lines 25-28 (photo 1). This sign is located at the beginning of platform 24 , which is situated on the right side of the main platform. However, at first sight, this sign seems well placed, large enough and thus clearly visible from the main platform. Therefore, the experiment described below was performed to identify clearly the problems encountered by travellers that try to reach this part of the station.

\subsection{Experimental protocol}

\subsubsection{Instructions}

At the beginning, the experimenter presented the experimental goals to the participant, in order to make him/her understand that only the faults of the train station were being evaluated, not himself or herself. According to [9], this instruction leads the 


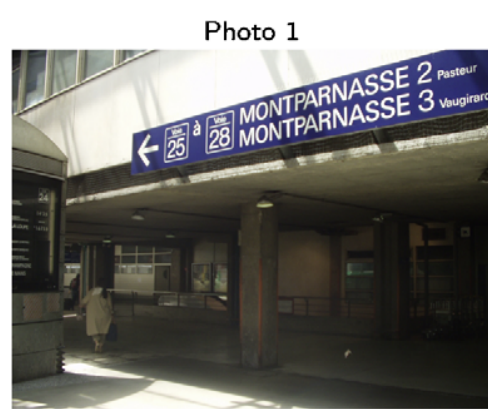

Photo 4

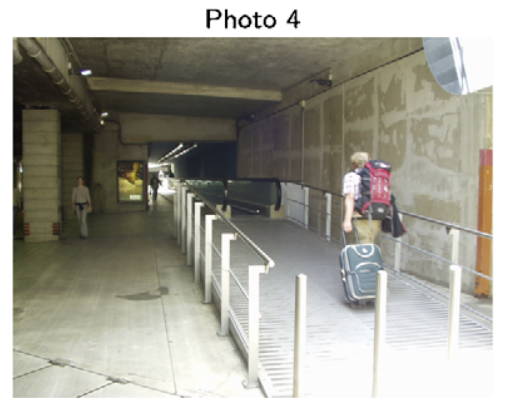

Photo 2

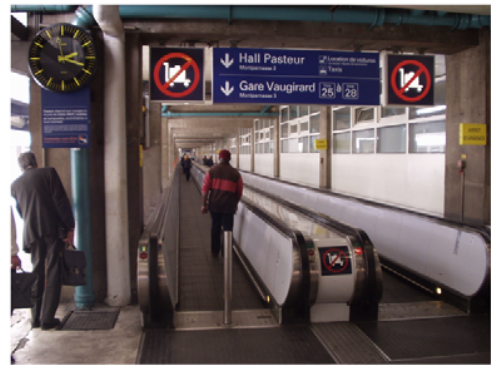

Photo 5

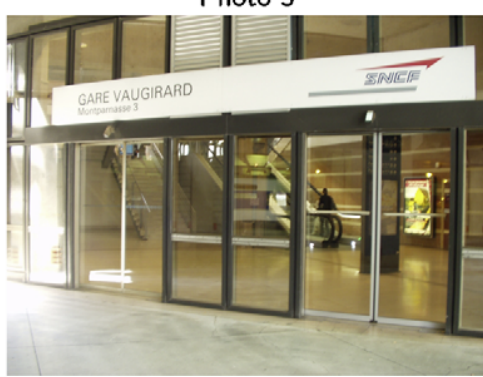

Photo 3

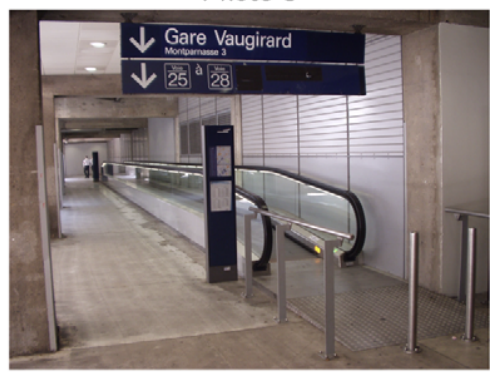

Gare Vaugirard $\downarrow \sqrt{25} \mathrm{a}^{28}$

Fig. 2. Photos taken along the path to Vaugirard hall, from the beginning of platform 24 . participant to have a more critical eye, which is very important for the experiment. Then the participant was given the following instruction: "You have to take the next train for Granville. ${ }^{1}$ You have an open ticket, so you do not know the exact schedule". Once the participant reports having clearly understood the instruction, he/she has to reach the goal without the help of the experimenter (for complete instructions, see Appendix A.1).

\subsubsection{Meeting point}

The meeting point is given at the subway exit, 15 min before the next train for Granville, but the participant does not yet know that. This meeting point is very important because it places the participant in a real situation of quick departure, each participant having $15 \mathrm{~min}$ to reach the goal. According to the station manager, this condition is more likely to create problems.

\subsubsection{Video}

The participant's entire walk was recorded on video by the experimenter, without interfering with the course of the experiment. A light, hand-held digital camera (Sony DCR-DVD306) was used in order to remain as discreet as possible.

\subsubsection{Interview}

Once the participant reached the goal, i.e., once he/she was ready to board the train for Granville, the video recording stopped, and the participant was taken to a meeting room for an individual interview. The goal of this interview was to have the participant explain the walk in detail during a replay of the video. The participant and the experimenter watched the video, and the participant described his/her actions, problems that had been encountered, information that had been looked for, etc. This interview was conducted according to interviewing techniques proposed by [12]. These techniques are used to help the interviewee describe explicitly the actions in which he/she was engaged. In our experiment, two aspects of this interview technique were particularly useful:

\footnotetext{
1 Trains for Granville leave from Vaugirard hall.
}

1. To open the dialogue between the participant and the experimenter, in order to make the participant feel free to talk. This was achieved with the following introductory sentence: "What I need to know is how you completed your walk. If you agree, I am going to ask you some questions, in order to understand together what you have done."

2. To restart the dialogue when the participant encounters difficulties explaining an action. For example, if a participant's description of an action is too sketchy, the experimenter can repeat his/her last sentence and try to make them start the description again.

\subsubsection{Participants}

The participants were selected according to two criteria: having a good experience in travelling by train, having no experience with this part of Montparnasse station (i.e., having no experience in taking a train leaving from lines $25-28$ in the Vaugirard hall). No musical background was required. Ten participants, four men and six women between 26 and 49 years of age, were then recruited and paid 15 euros for the experiment.

\subsection{Results}

In a first phase, the results of each participant were analyzed separately. Each video was analyzed by reporting all the actions that were visible on the video (e.g. turning left, taking a stair, looking at a sign, etc.). Then each interview was transcribed and analyzed in order to identify the problems encountered by the participant. In a second phase, a synthesis of all the participants' actions and problems was performed. This synthesis is presented in the next sections.

\subsubsection{The steps}

Given the actions taken by the participants and the problems reported in the interviews (for example, hesitation, unexpected direction), six main steps have been deduced according to the equipment (the first sign that indicates the location of lines 2528 , the three moving walkways) and to the architectural transitions (Vaugirard hall entrance). These steps are: the main platform, 
Table 1

Main steps of the walk for each participant. Each column corresponds to one step. A cross means that the step was completed by the participant without any difficulty.

\begin{tabular}{|c|c|c|c|c|c|c|c|}
\hline \multirow[t]{2}{*}{ Subject } & \multicolumn{7}{|l|}{ Main steps } \\
\hline & Main platform & lst sign & lst moving walkway & 2nd moving walkway & 3rd moving walkway & Vaugirard entrance & On time arrival \\
\hline FM & $\mathrm{X}$ & $\mathrm{X}$ & $\mathrm{X}$ & $\mathrm{X}$ & $\mathrm{X}$ & $\mathrm{X}$ & $\mathrm{X}$ \\
\hline $\mathrm{AB}$ & - & $\mathrm{X}$ & $\mathrm{X}$ & - & - & $\mathrm{X}$ & $\mathrm{X}$ \\
\hline CLC & - & $\mathrm{X}$ & $\mathrm{X}$ & - & $\mathrm{X}$ & $\mathrm{X}$ & $\mathrm{X}$ \\
\hline LD & $\mathrm{X}$ & $\mathrm{X}$ & $\mathrm{X}$ & $\mathrm{X}$ & $\mathrm{X}$ & $\mathrm{X}$ & $\mathrm{X}$ \\
\hline $\mathrm{KP}$ & $\mathrm{X}$ & $\mathrm{X}$ & - & - & $\mathrm{X}$ & $\mathrm{X}$ & $\mathrm{X}$ \\
\hline $\mathrm{CI}$ & $\mathrm{X}$ & $\mathrm{X}$ & $\mathrm{X}$ & $\mathrm{X}$ & $\mathrm{X}$ & $\mathrm{X}$ & $\mathrm{X}$ \\
\hline $\mathrm{CB}$ & $\mathrm{X}$ & $\mathrm{X}$ & $\mathrm{X}$ & - & $\mathrm{X}$ & $\mathrm{X}$ & $\mathrm{X}$ \\
\hline $\mathrm{JA}$ & $X$ & $\mathrm{X}$ & $X$ & $X$ & $X$ & $X$ & $\mathrm{X}$ \\
\hline MAT & $\mathrm{X}$ & $\mathrm{X}$ & $\mathrm{X}$ & - & - & - & $\mathrm{X}$ \\
\hline MPH & - & $\mathrm{X}$ & - & - & - & - & - \\
\hline Total & 7 & 10 & 8 & 4 & 7 & 8 & 9 \\
\hline
\end{tabular}

the three moving walkways, the Vaugirard hall entrance and the on-time arrival. According to the description of the situation in Section 2.2.2, a participant's performance was considered good when all the steps were completed without any difficulty, i.e., when the participant did not get lost on the main platform, took all the moving walkways, entered Vaugirard hall and arrived on time to take the train. Table 1 presents the performance of each participant for these six steps. This table shows that out of 10 participants, one did not enter Vaugirard hall and arrived too late to take the train (MPH), and another one did not enter the Vaugirard hall (MAT). In the interviews, all the participants reported a similar strategy: once they knew the line number of their train, they started to look for this line, i.e., they followed the sign that indicated "lines 25-28". The next paragraphs describe the problems encountered at each step of the walk.

2.4.1.1. Main platform and first sign. The first column shows that three participants encountered problems on the main platform (i.e., the one that is perpendicular to lines 1-24). These participants did not understand that they had to walk in the direction of the right end of the main platform. The interviews revealed that this difficulty was due to an ambiguity in the division of the lines into suburban and main lines. This is not a problem that directly concerns the access to the Vaugirard hall.

Column 2 of Table 1 shows that none of the participants had difficulty seeing the first sign indicating lines 25-28, contrary to what was presumed by the managers of Montparnasse Station (see Section 2.2).

2.4.1.2. The moving walkways. Columns 3 to 5 show that the moving walkways were not always taken. The two participants (KP and MPH), who did not take the first walkway, reported that the sign indicating lines 25-28 was not clearly visible when they arrived on platform 24 . The six participants that did not take the second walkway reported that there was an ambiguity between two signs that indicated the direction for lines $25-28$. These two signs are situated at two different positions. This ambiguity made them hesitate and not take the second moving walkway. In addition, the arrow drawn on the sign is not strictly located above the entrance of the second moving walkway (see photo 3 in Fig. 2). Finally, the three participants who did not take the third walkway explained that there was no sign (photo 4 in Fig. 2), so that nothing directed them to take it.

2.4.1.3. Vaugirard entrance. Column 6 shows that two of the 10 participants did not enter Vaugirard hall. In the interview, they explained that when arriving in front of the hall, there was no indication for lines 25-28 (photo 5 in Fig. 2). Indeed, the sign indicates "Gare Vaugirard-Montparnasse 3". In addition, the sign col- our is white, which is different from the blue ${ }^{2}$ used for all the signs indicating the direction for lines 25-28. This difference in colour created another ambiguity.

\subsubsection{Negative judgement}

All the participants reported a lack of information during the walk along the three moving walkways until they arrived at the target line in Vaugirard hall. They explained this lack of information in two ways. First, they talked about a lack of confirmation that they were walking in the right direction at each step of the walk. Second, because the walk is very long, they explained that information concerning the remaining distance to be covered was missing. The consequence of these two cases of lack of information was an increase in stress during the walk. More generally all the participants explained that they found the walk unpleasant because the distance was too long and the environment not very friendly.

\subsection{Conclusions}

This section presented the results of an ergonomic experiment on the analysis of the problems encountered by travellers in a train station. The results show that all these problems occurred between the beginning of platform 24 and the entrance of Vaugirard hall. Three kinds of problems were identified: (1) a problem of orientation was identified at the entrance of the three moving walkways and Vaugirard hall, i.e., participants did not understand that they had to go in that direction in order to reach the line more quickly, (2) the participants reported a lack of information confirming the direction taken, i.e., nothing confirmed that they were headed in the right direction, and (3) information concerning the remaining distance to be covered was also missing. It is important to emphasize that none of the problems reported here were related to the hypothetical problem of the sign that indicates the location of lines $25-28$.

The next phase of the study sought to find a sonic solution to the three identified problems. The next section presents the specification for the design of informative non-speech signals.

\section{Sound design specifications and selection to improve way- finding}

The goal of this phase was to propose sound signals that would resolve the way-finding problems identified previously. The sound design was based on functional specifications (Section 3.1) that

\footnotetext{
For interpretation of colour in Fig. 2, the reader is referred to the web version of this article.
} 
described the environmental characteristics of the places and the required functions of the sonic solution. These specifications were then given to a composer specializing in sound design whose task was to propose appropriate sound signals to ameliorate the problems (Section 3.2). Finally, a selection of the best sound signals was studied with a listening test in the laboratory (Section 3.3).

\subsection{Functional specifications}

\subsubsection{Environmental descriptions}

Two environmental descriptions were given to the sound designer. First, an architectural description gave the main physical characteristics of the walk between the beginning of platform 24 and the Vaugirard entrance: main distances, maps and photos were provided. Second, an acoustical description was provided: sound level measures, spectra and Ambisonic soundscape recordings. These descriptions helped the sound designer to create sounds that were appropriate to the acoustical properties of the soundscape.

\subsubsection{Three sound functions}

The functions of the sound signals must correspond to the problems identified in the experiment presented in Section 2. Thus, they must have three functions:

1. Orientation: The sound signals must direct the user to the entrance of the three moving walkways and Vaugirard hall. This function is called beacon sound according to previous studies in which this type of sound was used to indicate exits in an emergency situation [13] or to improve navigation in a virtual environment $[14,15]$.

2. Confirmation: The sound signals must confirm at each step of the walk that the direction taken is the right one. This signal, called feedback sound, must be heard just beyond the position of the beacon sound.

3. Timeline: The sound signals must inform the user, at each step, concerning the progression of the walk. In other words, hearing these sound signals, the travellers should understand that they are approaching the target. This function is called timeline.

\subsection{Sound design}

\subsubsection{The sound designer}

The functional specifications presented in the previous paragraphs were given to the fourth author, a sound designer and researcher working at IRCAM (Institut de Recherche et de Coordination Acoustique/Musique, Paris) during the project. In a previous study, he had performed experiments on sound signals for helping blind people to orient themselves in a Japanese train station [4]. In order to choose between several proposals, the composer was free to create different types of solutions according to the specifications. The next section describes the sound signals he proposed (see also [16]).

\subsubsection{Principles of design}

The composer designed sounds according the principle of "earcons", i.e., non-speech sounds that are created to convey specific information by means of an arbitrary relationship between the sound and its meaning [17]. These sounds are generally used in human-machine interfaces (HMI) to help perform basic operations on files in a computer, for example [18,19]. Principles for their creation have been proposed in order to adapt the features of a sound (timbre, intensity, etc.) to its function [20]. The type of sounds (earcons) is part of the designer's choice, which means that other types of sounds could have been proposed for the required functions, such as auditory icons (sounds that are caricatures of everyday sounds [21], used to convey information in a computer interface, for example [22]). The earcons proposed by the sound designer were built around two schemas, as presented below.

3.2.2.1. A pair for the beacon sound and feedback sound. For the first two functions, the sound designer decided to create two sounds that work together, according to a call-response schema. In other words, the feedback sound is a "response" to the beacon sound. Twenty pairs of sounds were proposed according to three different types of schemas (Table 2). For the dynamic schema, the pairs were built with a variation of five musical parameters: pitch, harmonic combination, dynamic profile, melodic profile and vibrato. For the harmonic schema, the other parameters were fixed, only the harmonic combination varied. For the melodic schema, the question-response was conceived according to classical musical principles (chord resolution, for example).

3.2.2.2. A sequence of four sounds for the timeline. For the timeline function, the sound designer proposed four different subsequences, placed at four steps between the beginning and end of platform 24 . This sequence of four subsequences was supposed to indicate that the end of the walk was approaching. The sound designer created 10 different sequences (Table 3), using different kinds of schemas to indicate the progress. The 10 schemas were based on different kinds of musical progressions in four subsequences. Sequence T01 was based on a harmonic progression: sub-dominant, two dominant chords and a tonic chord. In sequence T02, an arpeggio was played with internote intervals increasing from 5 to 20 semitones. In sequence $\mathrm{T} 03$, the number of notes in a given chord was decreased. Sequence T04 was a countdown from four beats to one beat. Sequence T05 was an arpeggio whose tempo increased progressively. Sequence T06 was based on a contour variation in a three-interval melody: three ascending intervals $(\nearrow)$, two ascending and one descending $(\nearrow-\nearrow-\searrow$ ), one ascending and two descending $(\nearrow-\searrow-\searrow$ ) and then three descending $(\searrow)$. Sequence T07 was based on a rhythmic variation in a four-note melody: three short and one long (oooO), two short, one long and one short (ooOo), one short, one long and two short (oOoo), then one long and three short (Oooo). In sequence T08, the vibrato speed was increased progressively. The sequence T09 was similar to T06, but with a pentatonic scale melody. Then, the four steps of sequence T10 used a common melody $\left({ }^{* * * *}\right)$ to which was added a second phrase made of a decreasing number of notes: from four (OOOO) to one $(0)$.

3.2.2.3. Tonality and musical scale. The fundamental frequency of the sound proposed was tuned to the "keynote" of the soundscapes of the train station. This aesthetic notion was introduced by the Canadian composer Murray Schafer [23] and consists of the part of the soundscape that is predominant. Using the acoustical descriptions of the soundscapes (see Section 3.1.1), two keynotes were found: the background noise, the spectral centroid ${ }^{3}$ of which was close to the note $C$, and the spoken announcement jingle which was built on a $\mathrm{C}$ scale. Consequently, Kawakami decided to adjust the fundamental frequency of all the earcons to $C$ or $G$ and to use a pentatonic scale.

\subsection{Sound selection in the laboratory}

The goal of this part was to select the sequences that would be installed in the train station for ergonomic validation, from among the proposals made by the sound designer presented previously. To

\footnotetext{
${ }^{3}$ The spectral centroid of a sound signal is the center of gravity of its frequency spectrum. It indicates the frequency at which signal energy is equal above and below it in the spectrum. Perceptually, it is close to the "sharpness" of the sound [24].
} 
Table 2

Description of the 20 pairs of sounds created by Kawakami for the functions beacon (B) and feedback (F). The column "Harmonic combination" indicates the number of harmonics (multiples of the fundamental frequency). The dynamic profile indicates whether the energy increases $(\nearrow$ ), decreases $(\searrow$ ) or does not change $(\rightarrow)$. The melodic profile indicates whether the melody contour is ascending $(\nearrow)$, descending $(\searrow)$ or flat $(\rightarrow)$. The vibrato indicates the speed of amplitude variation in beats per second $(\mathrm{Hz})$.

\begin{tabular}{|c|c|c|c|c|c|}
\hline Sound & Pitch (Hz) & Harmonic combination & Dynamic profile & Melodic profile & Vibrato $(\mathrm{Hz})$ \\
\hline \multicolumn{6}{|c|}{ Dynamic schema } \\
\hline B01 & 1200 & 2,3 & $\searrow$ & $\rightarrow$ & 0 \\
\hline F01 & 800 & 2,3 & $\searrow$ & $\rightarrow$ & 0 \\
\hline B02 & $800-1600$ & 2,3 & $\rightarrow$ & $\nearrow$ & 0 \\
\hline F02 & 800 & 2,3 & $\searrow$ & $\rightarrow$ & 0 \\
\hline B03 & $800-1600$ & 2,3 & $\rightarrow$ & $\nearrow$ & 13 \\
\hline F03 & 800 & 2,3 & $\searrow$ & $\rightarrow$ & 0 \\
\hline B04 & $800-1600$ & 2,3 & $\rightarrow$ & $\nearrow$ & 13 \\
\hline F04 & $1600-800$ & 2,3 & $\rightarrow$ & $\searrow$ & 13 \\
\hline B05 & 1200 & $2,3,4,5,6,7$ & $\searrow$ & $\rightarrow$ & 0 \\
\hline F05 & 800 & $2,3,4,5,6,7$ & $\searrow$ & $\rightarrow$ & 0 \\
\hline B06 & $800-1600$ & $2,3,4,5,6,7$ & $\rightarrow$ & $\nearrow$ & 0 \\
\hline F06 & 800 & $2,3,4,5,6,7$ & $\searrow$ & $\rightarrow$ & 0 \\
\hline B07 & $800-1600$ & $2,3,4,5,6,7$ & $\rightarrow$ & $\nearrow$ & 13 \\
\hline F07 & 800 & $2,3,4,5,6,7$ & $\searrow$ & $\rightarrow$ & 0 \\
\hline B08 & $800-1600$ & $2,3,4,5,6,7$ & $\rightarrow$ & $\nearrow$ & 13 \\
\hline F08 & $1600-800$ & $2,3,4,5,6,7$ & $\rightarrow$ & $\searrow$ & 13 \\
\hline \multicolumn{6}{|c|}{ Harmonic schema } \\
\hline B09 & 800 & $5,8,13,21,34,55$ & $\searrow$ & $\rightarrow$ & 0 \\
\hline F09 & 800 & $2,3,5,8,13,21$ & $\searrow$ & $\rightarrow$ & 0 \\
\hline B10 & $800+1200$ & $1,2,3,5,8,13$ & $\searrow$ & $\rightarrow$ & 0 \\
\hline F10 & 800 & $2,3,5,8,13,21$ & $\searrow$ & $\rightarrow$ & 0 \\
\hline B11 & $800+1200$ & $2,3,5,8,13,21$ & $\searrow$ & $\rightarrow$ & 0 \\
\hline F11 & 800 & $2,3,5,8,13,21$ & $\searrow$ & $\rightarrow$ & 0 \\
\hline B12 & Morph from 800 to 1200 & $5,8,13,21,34,55$ & $\searrow$ & $\rightarrow$ & 0 \\
\hline F12 & 800 & $2,3,5,8,13,21$ & $\searrow$ & $\rightarrow$ & 0 \\
\hline Sound & Profile & & & & \\
\hline \multicolumn{6}{|c|}{ Melodic schema } \\
\hline B13 & Increase & & & & \\
\hline F13 & Decrease, tonic resolution & & & & \\
\hline B14 & Increasing frequency & & & & \\
\hline F14 & Part of B14 & & & & \\
\hline B15 & Increasing melody & & & & \\
\hline F15 & B15 reverse and shorter & & & & \\
\hline B16 & Movement & & & & \\
\hline F16 & Stop, same fifth interval as & & & & \\
\hline B17 & Call & & & & \\
\hline F17 & Response with same mode & & & & \\
\hline B18 & Same scale & & & & \\
\hline F18 & Same scale & & & & \\
\hline B19 & Increasing profile & & & & \\
\hline F19 & Decreasing profile & & & & \\
\hline $\mathrm{B} 20$ & Long rythm & & & & \\
\hline F20 & Short rythm, tonic resolut & & & & \\
\hline
\end{tabular}

Table 3

Description of the 10 sequences of four subsequences created by Kawakami for the timeline function.

\begin{tabular}{|c|c|c|c|c|c|}
\hline Sequence & Schema & 1 & 2 & 3 & 4 \\
\hline T01 & Harmonic & Sub-dominant & Dominant & Dominant & Tonic \\
\hline T02 & Interval & 5 Semitones & 10 & 15 & 20 \\
\hline T03 & Chord & 5 Notes & 4 & 3 & 2 \\
\hline T04 & Countdown & 4 Notes & 3 & 2 & 1 \\
\hline T05 & Length & Slow Arpeggio & Faster & Faster & Faster \\
\hline T06 & Melody & $\nearrow$ & $\nearrow-\nearrow-】$ & $\nearrow-\searrow-\searrow$ & $\searrow$ \\
\hline T07 & Rythm & 0000 & ooOo & oOoo & Oooo \\
\hline T08 & Vibrato & Slow & Faster & Faster & Faster \\
\hline T09 & Pentatonic scale & $\nearrow-\searrow$ & $\nearrow$ & $\searrow$ & $\searrow-\nearrow$ \\
\hline T10 & Rythm+melody+countdown & ${ }^{* * * *} 0000$ & $* * * * 000$ & ${ }^{* * * * *} \mathrm{OO}$ & $* * * * O$ \\
\hline
\end{tabular}

achieve this goal, an experiment was carried out in which participants had to choose the sequences they preferred in terms of functionality, i.e., which sequences best fulfilled the three functions. The experiment was divided into two steps. The first one concerned the beacon-feedback pair, and the second one concerned the timeline sequence.

\subsubsection{Stimuli}

In step 1 , stimuli were the 20 pairs of subsequences created for the beacon-feedback functions (see Section 3.2). In step 2, stimuli were the 10 sequences of four subsequences created for the timeline function. The participants were seated in a double-walled IAC sound booth. The stimuli were amplified by a Yamaha P2075 stereo 
amplifier and presented binaurally over a set of Sennheiser HD 250 linear II headphones.

In a preliminary experiment, the two groups of stimuli were equalized in loudness with 10 participants. In this experiment, the participants had to adjust the level of each sound to match that of the reference sound (F01 for the beacon-feedback equalization and T08-1 for the timeline equalization, see Tables 2 and 3), the level of which was fixed at $56 \mathrm{~dB}(\mathrm{~A})$.

\subsubsection{Participants}

Thirty participants ( 15 women and 15 men, between 26 and 49 years of age) were recruited and paid for this experiment. None of them reported having hearing loss. No musical background was required. Before each step, the functions of the sounds were explained to the participants, and a description of the train station was given (photos and map).

\subsubsection{Procedure}

In each of the two steps of the experiment, the task was the same. Using the computer interface, ${ }^{4}$ participants were asked to choose the three preferred stimuli in terms of functionality and to classify them from the most to the least preferred. They could listen to the stimuli as many times they wished to. They could not interrupt the sound until it ended.

\subsubsection{Results}

Each sound was given a weighting $N$ that was calculated as follows: $N=3 * n 1+2 * n 2+n 3$, where $n 1$ is the number of times that the sound was classified in first position (i.e., the most preferred), $n 2$ in second position and $n 3$ in third position. Results for the beacon-feedback pair and for the timeline sequence are presented in Tables 4 and 5, respectively. For the beacon-feedback function, the pair P18 is the one with the highest weighting (29). This pair corresponds to the call-response schema composed of an increasing melody for the beacon (B18 in Table 2) and two decreasing notes from the same scale for feedback (F18 in Table 2). For the timeline function, the sequence T04 was the one with the highest weighting. This sequence is based on a countdown schema (see Table 2).

\section{Sound signalling system installation and evaluation of its ability to eliminate way-finding problems}

This last phase is an evaluation of the sound signals discussed previously in the real context of the train station. First, a sound signalling system was installed in the station using several speakers and IR sensors to trigger the sounds (Section 4.1). Then, an experiment was performed with new recruited travellers (Sections 4.2 and 4.3), using the same kind of procedure as in the first phase (see Section 2).

\subsection{Installation of the sound system}

This section presents the installation of the sounds selected previously. The selected sounds and a $2 \mathrm{D}$ animation presenting the general principle of the installation are available on the following website: http://julientardieu.free.fr/sounddesign.

\subsubsection{Principles}

The sounds were broadcast over stand-alone loudspeakers (ref: TOA EV20A) all along the walk from the beginning of the first moving walkway to the entrance of Vaugirard hall. Each loudspeaker

\footnotetext{
${ }^{4}$ Interface programmed with PsiExp, a software environment for the creation of psychoacoustic experiments developed by [25].
}

Table 4

Classification score for the beacon-feedback pairs of sounds.

\begin{tabular}{llllll}
\hline Sequences & Weighting & \multicolumn{4}{l}{ Number of times classified } \\
\cline { 2 - 6 } & & 1,2 or 3 & 1 & 2 & 3 \\
\hline P18 & 29 & 14 & 6 & 3 & 5 \\
P01 & 19 & 9 & 3 & 4 & 2 \\
P15 & 18 & 8 & 2 & 6 & 0 \\
P19 & 16 & 6 & 4 & 2 & 0 \\
P14 & 16 & 7 & 2 & 4 & 2 \\
P20 & 15 & 10 & 1 & 3 & 6 \\
P13 & 15 & 7 & 3 & 2 & 2 \\
P16 & 15 & 7 & 3 & 2 & 2 \\
P03 & 9 & 3 & 3 & 0 & 0 \\
P17 & 8 & 5 & 1 & 1 & 3 \\
P07 & 5 & 2 & 1 & 1 & 0 \\
P02 & 4 & 3 & 0 & 1 & 2 \\
P09 & 3 & 2 & 0 & 1 & 1 \\
P12 & 3 & 1 & 1 & 0 & 0 \\
P05 & 1 & 1 & 0 & 0 & 1 \\
P06 & 1 & 1 & 0 & 0 & 1 \\
P08 & 1 & 1 & 0 & 0 & 1 \\
P10 & 1 & 1 & 0 & 0 & 1 \\
Pll & 1 & 1 & 0 & 0 & 1 \\
P04 & 0 & 0 & 0 & 0 & 0 \\
\hline
\end{tabular}

Table 5

Classification score for the timeline sequence of sounds.

\begin{tabular}{llllll}
\hline Sequences & Weighting & \multicolumn{4}{l}{ Number of times classified } \\
\cline { 3 - 6 } & & 1,2 or 3 & 1 & 2 & 3 \\
\hline T04 & 51 & 22 & 11 & 7 & 4 \\
T03 & 30 & 14 & 6 & 4 & 4 \\
T05 & 29 & 14 & 5 & 5 & 4 \\
T02 & 24 & 13 & 4 & 3 & 6 \\
T09 & 14 & 7 & 2 & 3 & 2 \\
T10 & 9 & 6 & 1 & 1 & 4 \\
T06 & 8 & 6 & 0 & 2 & 4 \\
T07 & 8 & 4 & 1 & 2 & 1 \\
T01 & 5 & 3 & 0 & 2 & 1 \\
T08 & 2 & 1 & 0 & 1 & 0 \\
\hline
\end{tabular}

contained a memory card onto which a sound was loaded. The sound could be triggered by an internal movement sensor (see Fig. 3, left), or by an external movement sensor (see Fig. 3, right). In other words, the sounds were broadcast only when a traveller walked in front of the movement sensor. In one case, the movement detection was made right next to the speaker (internal sensor), and in the second case the detection was made remotely (external sensor). The remote detection was used only for the triggering of the beacon sound.

\subsubsection{Description}

Eight loudspeakers and three external movement sensors were installed in the train station, as presented in Fig. 4. Speakers 1, 3, 5, and 7 all broadcast the same sound: the beacon sound. Speakers 2 , 4,6 , and 8 broadcast the feedback sound followed by the timeline sequences (4-, 3-, 2- and 1-note sequences, respectively). The system was used for 3 weeks without interruption.

\subsection{Experimental protocol}

The selected sounds and the signalling system were designed to solve the various problems encountered by the travellers during the analysis phase of the pathway in Section 2. Thus, this in situ experiment aimed to evaluate the sound signalling system on the same pathway. The method is also based on the same experiment as the one used in Section 2 for the analysis phase. 

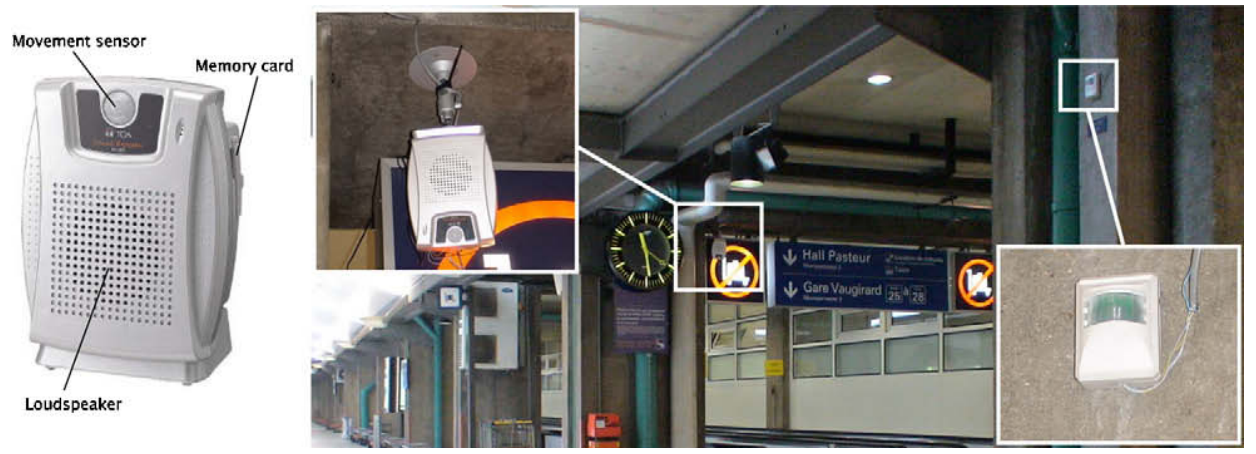

Fig. 3. Left: stand-alone loudspeaker used for the sound signalling system in Montparnasse Station. Right: loudspeaker in place with an external movement sensor.

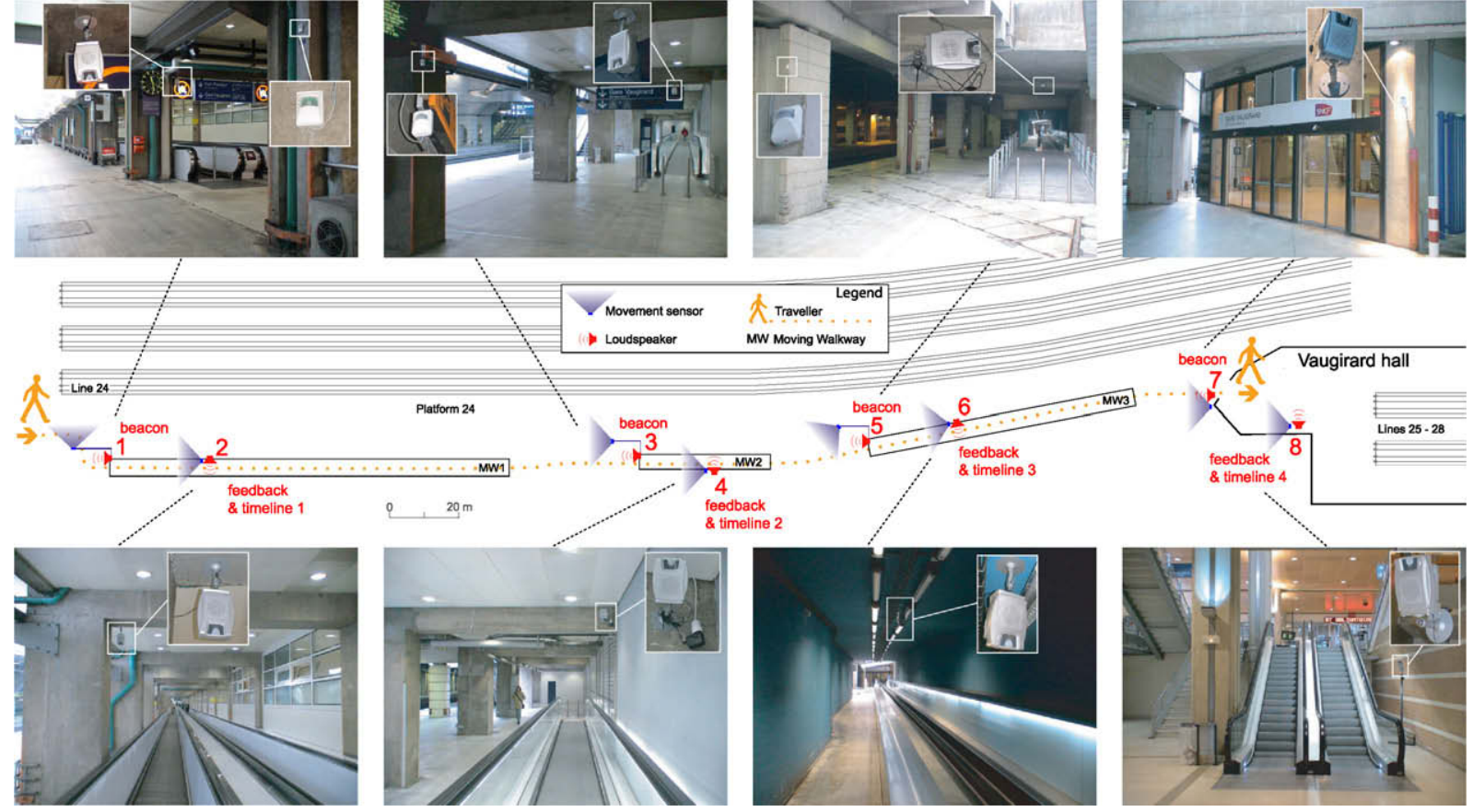

Fig. 4. Sound signalling system for the Montparnasse train station.

\subsubsection{Instructions}

The introductory part of the instructions was kept identical to that of the first experiment (see Section 2.3.1 and Appendix A.2 for complete instructions). Then, in addition to their main task (i.e., to take the next train to Granville), they were instructed to pay careful attention to the sound signals.

\subsubsection{Meeting point}

The meeting point was the same as presented in Section 2.3.2.

\subsubsection{Video}

The video recording of the walk was performed identically to that described in Section 2.3.3.

\subsubsection{Interview}

As in the first experiment, each walk was followed by an individual interview during which the participant explained the walk in detail with the help of the video replay. In addition, the participant was asked to explain whether the sounds helped him/her and how they did help.

\subsubsection{Participants}

The participants were selected according to the same criteria used in the first experiment (see Section 2.3.5). Eight new participants (five women and three men, between 20 and 50 years of age) were then recruited and paid 15 euros for this experiment.

\subsection{Results}

The results were analyzed in the same way as in the first experiment (see Section 2.4). In addition, each interview was analyzed in order to show whether the sounds helped the participants or not.

\subsubsection{The steps}

In a similar fashion as for the first experiment (see Table 1), Table 6 presents how each participant completed each of the main steps of the walk. A step was completed without problem when the participant walker in a direction coherent with the expected path to Vaugirard hall. This table shows that out of eight participants, only one encountered difficulties along the walk. 
Table 6

Main steps of the walk for each participant. Each column gives one step. A cross means that the participant completed the step without any difficulty. The exclamation point means that for the participant DP, the second moving walkway was out of order.

\begin{tabular}{|c|c|c|c|c|c|c|c|}
\hline \multirow[t]{2}{*}{ Subject } & \multicolumn{7}{|l|}{ Main steps } \\
\hline & Main platform & lst sign & lst moving walkway & 2nd moving walkway & 3rd moving walkway & Vaugirard entrance & On time arrival \\
\hline VS & $\mathrm{X}$ & $\mathrm{X}$ & $\mathrm{X}$ & $\mathrm{X}$ & $\mathrm{X}$ & $\mathrm{X}$ & $\mathrm{X}$ \\
\hline JD & $\mathrm{X}$ & $\mathrm{X}$ & $\mathrm{X}$ & $\mathrm{X}$ & $\mathrm{X}$ & $\mathrm{X}$ & $\mathrm{X}$ \\
\hline VL & $\mathrm{X}$ & $\mathrm{X}$ & $\mathrm{X}$ & $\mathrm{X}$ & $\mathrm{X}$ & $\mathrm{X}$ & $\mathrm{X}$ \\
\hline DP & - & $\mathrm{X}$ & $\mathrm{X}$ & $!$ & - & $\mathrm{X}$ & $\mathrm{X}$ \\
\hline SL & $\mathrm{X}$ & $\mathrm{X}$ & $\mathrm{X}$ & $\mathrm{X}$ & $\mathrm{X}$ & $\mathrm{X}$ & $\mathrm{X}$ \\
\hline JM & $\mathrm{X}$ & $\mathrm{X}$ & $\mathrm{X}$ & $\mathrm{X}$ & $\mathrm{X}$ & $\mathrm{X}$ & $\mathrm{X}$ \\
\hline DS & $\mathrm{X}$ & $\mathrm{X}$ & $\mathrm{X}$ & $\mathrm{X}$ & $\mathrm{X}$ & $\mathrm{X}$ & $\mathrm{X}$ \\
\hline $\mathrm{TF}$ & $\mathrm{X}$ & $\mathrm{X}$ & $\mathrm{X}$ & $\mathrm{X}$ & $\mathrm{X}$ & $\mathrm{X}$ & $\mathrm{X}$ \\
\hline Total & 7 & 8 & 8 & 7 & 7 & 8 & 8 \\
\hline
\end{tabular}

\subsubsection{The problems encountered}

DP had difficulties on the main platform, for a reason similar to the one identified in the first experiment (i.e., division of the lines into suburban and main lines). In addition, DP hesitated a lot at each step of the walk because of lack of information. This confirms the results of the first experiment. Otherwise, the other participants did not encounter any problem during the walk.

\subsubsection{The role of the sounds}

Out of the eight participants, all of them noticed the sounds and found them useful for their walk. Table 7 presents the perceived functions of the sounds, reported by each participant in the interview. The first column presents how the beacon sound was understood by the eight participants, i.e., the sound broadcast by loudspeakers 1, 3, 5 and 7 (see Fig. 4). The second column presents how the feedback and timeline sounds (loudspeakers 2, 4, 6 and 8 on Fig. 4) were understood.

This table shows that out of the eight participants, seven understood the confirmation given by the feedback sound. Only JD did not understand this function, but this participant explained in the interview that this function was already perceived in the beacon sound. This means that for JD, the beacon sound had both orientation and confirmation functions. This was also the case for participants VS and DS. Therefore, out of the eight participants, seven understood the orientation given by the beacon sound. For participant VL, all the sounds had the same function: confirmation. On the other hand, this table shows that none of the participants understood the function given by the sequence of timeline sounds. More generally, all eight participants appreciated the presence of sound signals, and indeed they all reported in the interviews that the sounds accompanied them all along the walk.

\subsection{Conclusions}

The previous section presented the results of an ergonomic experiment on the validation of sound signals in real conditions. The results show that a large majority of the participants understand two out of the three functions carried by the sound se-

Table 7

Perceived functions of the sounds. Summary of the interview analysis.

\begin{tabular}{lll}
\hline Subjects & Perceived functions & \\
\cline { 2 - 3 } & Beacon sound & Feedback and Timeline sounds \\
\hline VS & Orientation and confirmation & Confirmation \\
JD & Orientation and confirmation & - \\
VL & Confirmation & Confirmation \\
DP & Orientation & Confirmation \\
SL & Orientation & Confirmation \\
JM & Orientation & Confirmation \\
DS & Orientation and confirmation & Orientation and confirmation \\
TF & Orientation & Confirmation \\
\hline
\end{tabular}

quences: the orientation given by the beacon sound and the confirmation given by the feedback sound. However, the third function (timeline) was not understood. This could be explained in two different ways: (1) the timeline and confirmation sounds were too close in time and thus were not distinguished, or (2) the four steps of the timeline sound were not explicit enough when heard in a real context and thus would require a learning phase. More generally, the sound signals have a positive global effect on the soundscape of this part of the train station, and all the participants appreciated being accompanied by the sounds.

\section{General conclusion}

The study presented in this paper proposes a method to create sound signals in order to solve problems encountered by travellers in a train station. The method is composed of three steps that were applied in the case of a train station in Paris (Montparnasse Station).

First, an ergonomic experiment based on a method proposed in $[8,10,11]$ was carried out in the train station with 10 recruited participants who were asked to attain a specific goal (i.e., a train leaving from Vaugirard hall, a remote part of the train station), and to describe their walk during a subsequent individual interview. The analyses of the walks and the interviews showed that participants encountered several problems in attaining the set goal. Three kinds of problems were encountered: (1) orientation towards the entrance of the moving walkways and the entrance of Vaugirard hall, (2) lack of information confirming that they were headed in the right direction, and (3) a lack of information indicating the remaining distance until the end of the walk. This first experiment was particularly useful in determining precisely the difficulties encountered by travellers who want to reach this part of the train station.

Second, sound signals were created and installed in the train station, in order to solve the three problems identified previously. They were created by a sound designer $[4,16]$ who was given functional and environmental specifications. The specifications were the three functions of the sound signals that correspond to the identified problems: orientation, confirmation and timeline. The sound designer created several non-speech sound signals (earcons) according to principles mainly reported in [18] and [23]. An arbitrary choice from among the proposals made by the sound designer could have been done, but this does not mean that any kind of sound is possible. Indeed, the sound proposed for the confirmation (feedback sound) is a "response" to the sound for the orientation (beacon sound). Therefore, the sounds to be installed were selected in the laboratory based on ratings by 30 participants who were asked to choose the sound they preferred given the function they were to fulfil. The sound signals were installed in the train station, using an experimental broadcasting system made of eight stand-alone loudspeakers triggered by internal or external movement sensors. 
Third, another ergonomic experiment was carried out with newly recruited participants, in order to evaluate the sound signals under real conditions. The results show that most of the sound signals were understood and helped people during their walk. Only the sounds for the timeline function were not understood at all. This could be the result of an ambiguity with the preceding sound (the feedback sound), or just the difficulty to interpret this specific sound information without any pretraining session. The method deployed was therefore useful in evaluating the efficiency of new sound signals, coherently with the conclusion of the work presented in [9]. In conclusion, the study presented in this paper shows that way-finding problems encountered by users of a public space, such as a train station, can be reduced by non-speech sound signals if users are made aware of their existence. The proposed method has been particularly useful for both the identification of the functions that the sound must fulfil and the evaluation of the sounds once installed in real conditions. In other words, it is possible to create sound signals for public spaces that not only fit the users perception, but also take into account the course of their activities. The results are successful, because most of the sounds were understood and used by the participants. In terms of sound design in public places, this paper reinforces a methodical approach by providing a new way to specify and to evaluate new sound signals created in order to help users of a public space. This approach could be integrated into the design of a fully operational sound signalling system for a train station or any large public space. Future research could also take into account users with visual impairments. Since the success of this study, the French railway has installed in the same station a new sound system for visually impaired users called "the sound arrow" (http:// www.accessibilite.sncf.fr/mvh/sections/public).

\section{Acknowledgements}

This study was a part of a doctoral research project sponsored by the SNCF and the Association Nationale pour la Recherche Technique. The sound installation was made with the support of the station managers and the technical staff of the train station. We would like to thank Jacques Theureau for the fruitful discussions on method.

\section{Appendix A. Text instructions used for the two experiments in the train station}

\section{A.1. First experiment (analysis phase)}

\section{Introduction}

Cette étude porte sur la gare Montparnasse et a pour objectif d'identifier les défauts de cette gare du point de vue de l'usager. Nous cherchons donc les problèmes rencontrés par les voyageurs lors de leurs trajets dans la gare.

C'est pourquoi nous vous demandons d'effectuer un trajet dans la gare.

(This study concerns Montparnasse Station and aims to identify its lacks from the user's point of view. Thus we are looking for the problems encountered by the travellers in the station.

So we ask you to perform a walk in the station.)

\section{Tâche. (Task)}

L'objectif de votre trajet est de prendre un train pour GRANVILLE dès que possible. Il vous a été donné un billet ouvert, donc vous ne connaissez pas l'horaire exact.

Nous vous demandons d'effectuer ce trajet le plus naturellement possible, comme si vous deviez prendre le train pour des raisons personnelles.
Après le trajet, nous effectuerons ensemble un entretien lors duquel vous pourrez expliquer comment s'est passé le trajet.

(Your goal is to take the next train that goes to GRANVILLE as soon as possible. You've been given an open ticket, so you don't know the exact time schedule.

We ask you to perform this walk as naturally as possible, as if you had to take this train for personal reasons.

After the walk, we'll have an interview together, and you will have the opportunity to explain how your walk proceeded.)

\section{A.2. Second experiment (sound signalling evaluation)}

\section{Introduction}

Cette étude porte sur la gare Montparnasse et a pour objectif d'identifier les défauts de cette gare du point de vue de l'usager. Nous cherchons donc les problèmes rencontrés par les voyageurs lors de leurs trajets dans la gare.

C'est pourquoi nous vous demandons d'effectuer un trajet dans la gare.

(This study concerns Montparnasse Station and aims to evaluate a new sound signalling system. This system is made of sound signals broadcast by loudspeakers installed at different places.

So we ask you to perform a walk in the station.)

Tâche. (Task)

L'objectif de votre trajet est de prendre un train pour GRAN-

VILLE dès que possible. Il vous a été donné un billet ouvert, donc vous ne connaissez pas l'horaire exact.

Nous vous demandons d'effectuer ce trajet en étant particulièrement attentif(-ve) aux signaux sonores qui seront émis.

Après le trajet, nous effectuerons ensemble un entretien lors duquel vous pourrez expliquer comment s'est passé le trajet, et ce que les sons vous ont apporté.

(Your goal is to take the next train that goes to GRANVILLE as soon as possible. You've been given an open ticket, so you don't know the exact time schedule.

We ask you to pay careful attention to the sound signals that will be broadcast.

After the walk, we'll have an interview together, and you will have the opportunity to explain how your walk proceeded, and the extent to which the sounds were useful.)

\section{References}

[1] Weisman J. Evaluating architectural legibility. Way-finding in the built environment. Environ Behav 1981;13(2):189-204.

[2] O'Neill MJ. Effects of signage and floor plan configuration on way-finding accuracy. Environ Behav 1991;23(5):553-74.

[3] Loomis JM, Klatzky R, Golledge RG. Navigating without vision: basic and applied research. Optomet Vis Sci 2001;78 (5).

[4] Kawakami H. Sign-on: report on the study and survey of sound design, mode free from the barriers from to auditory sense. Technical report, The Japan Sign Design Association (SDA); 2000.

[5] Tardieu J, Susini P, Poisson F. Soundscape design in train stations: perceptual study of soundscapes. In: Proceedings of the CFA/DAGA (Joint French/German acoustical societies meeting), Strasbourg; March 2004.

[6] Tardieu J, Susini P, Poisson F, McAdams S. Soundscape design in train stations. In: Proceedings of the Journées design sonore, Paris; October 2004.

[7] Tardieu J, Susini P, Poisson F, Lazareff P, McAdams S. Perceptual study of soundscapes in train stations. Applied Acoustics 2007. doi:10.1016 j.apacoust.2007.10.001.

[8] Theureau J. Cours d'action. In: Vocabulaire de l'ergonomie. Octarès; 1995. p. 98-104.

[9] Theureau J. L'émergence d'un complexe d'échanges à travers les trajets des voyageurs: essai méthodologique. In: Bayart $\mathrm{D}$, Borzeix $\mathrm{A}$, Lacoste $\mathrm{M}$, editors. Les traversées de la gare: la méthode des trajets pour analyser l'informationvoyageurs, vol. 118. Paris: RATP-Département du développement-Mission prospective et recherches sociales; 1997. p. 145-90.

[10] Theureau J. Le cours d'action: méthode élémentaire. 2nd ed. Octarès; 2004.

[11] Theureau J. Course-of-action analysis and course-of-action centered design. In: Hollnagel E, editor. Handbook of cognitive task design. Lawrence Erlbaum Ass: 2003. p. $55-81$. 
[12] Vermersch P. L'entretien d'explicitation. 3rd ed. ESF; 2000.

[13] Rutherford P, Withington D. The application of virtual acoustic techniques for the development of an auditory beacon used in building emergency egress. In: International conference on auditory display (ICAD), Espoo, Finland; July 2001.

[14] Walker B, Lindsay J. Effect of beacon sounds on navigation performance in a virtual reality environment. In: Proceedings of the international conference on auditory display (ICAD), Boston; July 6-9 2003.

[15] Walker B, Lindsay J. Auditory navigation performance is affected by waypoint capture radius. In: Proceedings of the international conference on auditory display (ICAD), Sydney, Australia; July 6-9 2004.

[16] Kawakami H, Tardieu J, Susini P, Poisson F. The sound navigation system at Montparnasse station. In: Proceedings of the world forum for acoustic ecology, Hirosaki, Aomori, Japan, November 2-6; 2006.

[17] Blattner MM, Sumikawa DA, Greenberg RMM. Earcons and icons: their structure and common design principles. Hum-Comput Interact 1989;4: $11-44$.
[18] Brewster S. Non-speech auditory output. In: The human computer interaction handbook. Lawrence Erlbaum Associates; 2002. p. 220-39 [chapter 12].

[19] Brewster S, Wright PC, Edwards ADN. A detailed investigation into the effectiveness of earcons. In: Auditory display. Sonification, audification, and auditory interfaces. Addison-Wesley; 1994.

[20] Brewster S, Wright P, Edwards A. Experimentally derived guidelines for the creation of earcons. In: Human computer interaction. Huddersfield, UK; 1995.

[21] Gaver WW. Everyday listening and auditory icons. PhD thesis, University of California, San Diego; 1988.

[22] Gaver WW. The sonicfinder: an interface that uses auditory icons. HumComput Interact 1989;4:67-94.

[23] Schafer RM. The tuning of the world. Random House Inc.; 1977.

[24] Zwicker E, Fastl H. Psychoacoustics. Berlin: Springer; 1999.

[25] Smith B. PsiExp: an environment for psychoacoustic experimentation using the IRCAM musical workstation. In: Society for music perception and cognition conference'95, University of California, Berkeley; 1995. 